ISSN 1112-9867

http://www.jfas.info

\title{
STUDY OF ANTIOXIDANT ACTIVITY AND FREE RADICAL SCAVENGING POWER OF RHEUM RIBES FLOWER EXTRACT
}

\author{
M. M. Nemat Shahi*1, A. H. Elhami $\operatorname{Rad}^{2}$, N. Nemat Shahi ${ }^{3}$, M. R. Bakhsh Amin ${ }^{4}$
}

${ }^{1}$ Young Researchers and Elite Club, Sabzevar Branch, Islamic Azad University, Sabzevar, Iran

${ }^{2}$ Department of Food Science and Technology, Sabzevar Branch, Islamic Azad University,

Sabzevar, Iran

${ }^{3} \mathrm{Ph}$.D Student in Biology - Plant Physiology, Faculty of Basic Sciences, Ferdowsi University of Mashhad, Mashhad, Iran

${ }^{4}$ Quality Control Manager of Tomate Agro-Industry Company of Khoshab factories

Published online: 15 May 2016

\begin{abstract}
In recent years, the use of synthetic antioxidants and the degradation products derived from them is limited, because they are toxic and carcinogenic. So, studying on the use of natural antioxidants to replace the synthetic antioxidants is very important. Natural antioxidants are healthier and have more benefits and fewer harmful side effects. In this study, first, the Rheum Ribes of flower was extracted by maceration method with methanol. The extract's phenolic compounds and inhibitory activity of free radicals were evaluated in different concentrations (100, 150, 200, 250 and 300 ppm) by Folin-Ciocalteu method and DPPH test, respectively and then, compared with the synthetic antioxidant of BHT at the constant concentration of $200 \mathrm{ppm}$. The results showed that the highest antioxidant properties of the extract was related to the concentration of $300 \mathrm{ppm}$ and also the concentration of $250 \mathrm{ppm}$ of the extract of Rheum Ribes of flower was equivalent to a concentration of $200 \mathrm{ppm}$ of BHT in terms of free radical scavenging properties.
\end{abstract}

Author Correspondence, e-mail: m.nematshahi67@gmail.com

doi: http://dx.doi.org/10.4314/jfas.v8i3s.38 
Key words: Rheum Ribes flower, Free radical scavenging power, Natural antioxidants, Phenolic compounds.

\section{INTRODUCTION}

Oxidation of oils reduces the nutritional value and storage life of oil in addition to changing the organoleptic characteristics of food and also it is harmful to the health of consumers because of the production of undesirable compounds in oil. There are several ways to prevent the oxidation and one of them is adding antioxidants. The antioxidants are compounds which are able to delay, reduce and even stop the oxidation processes. Today, the synthetic antioxidants, such as BHA, BHT, TBHQ and gallates are used for this purpose. However, given to the adverse effects of synthetic antioxidants such as the mutagenicity and carcinogenic effects in human body, they have been gradually removed from the list of consumption antioxidants, so, producing natural antioxidants as a suitable replacement is necessary. Bera et al. (2006) stated that the advantages of natural antioxidants are the high acceptance by consumers and their safety in compared with synthetic antioxidants (7). So, studying on natural antioxidants in order to replace the synthetic antioxidants is necessary. Also, the studies on the effects of natural antioxidants on edible oils indicate that the natural antioxidants increase the nutritional value in addition to the stability of edible oils (7). Herbal medicine is an important part of the treatment system in Iran and Rheum Ribes is one of the known plants in herbal medicine and no studies have been performed on the antioxidant effects of its flower in Iran. Rheum Ribes is a perennial plant, of Oxalidaceae and Magnoliopsida without petals and has two very large and green leaves. It has straight and two-sided stem which comes out from the middle of the plant. Rheum Ribes contains the vitamins of $\mathrm{A}, \mathrm{B}_{1}, \mathrm{~B}_{2}$ and $\mathrm{C}$ and also some elements such as potassium, magnesium and calcium, and some organic acids such as citric acid and malic (2).

Different studies have been performed on the extraction of natural antioxidants from medicinal plants that some of them referred as follows. Latoui et al. (2012) evaluated the leaf, root and seed of Vitex agnus-Castus in terms of phenolic compounds, total polyphenols, diphenol, flavonoids and anthocyanins for the first time. Based on their results, the highest 
amount of total polyphenols and 2-phenols were related to the methanol extract of Vitex agnus-Castus's leaf. Given that the methanol extract of its leaf had a high antioxidant properties, it was introduced as a cheap and convenient source of phenolic compounds for food and pharmaceutical industries (10). Shahsavari et al. (2008) studied on the antioxidant effect of the Zataria Mulifloraboiss's essence on the soybean oil. They analyzed the essence by GC/MS device and identified its major chemical components. The results showed that the Carvacrol (26.08\%) and Thymol (17.23\%) were the main phenolic compounds of the essence. The antioxidant activity of the extract was evaluated by measuring the number of peroxide and thiobarbituric acid of soybean oil (oven test) and it was concluded that the essence of Zataria Mulifloraboiss, in the concentration of $0.1 \%$, has an antioxidant effect equivalent to BHA and also it has it in the concentration of $0.02 \%$ in the soybean oil. Therefore, this essence has a good antioxidant property and can be used as a natural antioxidant in some foods after performing the additional tests on it (3). Kamkar (2009) determined the antioxidant activity of the Dill's (Anethum graveolens) essence by using two methods of 2,2-diphenyl-1-picrylhydrazyl based on the percentages of inhibitory activity of free radicals and inhibitory activity of linoleic acid oxidation in the system of beta-carotene-linoleic acid. The results showed that the antioxidant power of ethanolic extract was significantly more than the antioxidant power of the essence $(\mathrm{p}<0.05)$ and it can be due to the different amount of their phenolic compounds. There is a strong correlation between the antioxidant power and the amount of phenolic compounds. The antioxidant power of butylated hydroxy toluene was more than the antioxidant power of Dill's essence and ethanolic extract (6).

The purpose of this study is evaluating the antioxidant properties of the extract of Rheum Ribes flower and comparing it with the synthetic antioxidant of BHT at the concentration of $200 \mathrm{ppm}$ in order to replace synthetic preservatives by natural antioxidants.

\section{MATERIALS AND METHODS}

\section{1-2- Extraction of Rheum Ribes flower}

One variety of Rheum Ribes flowers was provided from the local market of Sabzevar City. First, the waste was removed from them and they were washed. Then, they were dried at the 
temperature of $25^{\circ} \mathrm{C}$ and completely powdered by mill (Kenwood, model CG 100). To prepare the extract by maceration method, the powder was sifted and mixed with methanol as a mixing ratio of 1:10 (weight-volume) and put in hot plate with the rate of $250 \mathrm{rpm}$ for 24 hours at ambient temperature and then under vacuum, it was filtrated by Whatman filter paper No. 1. After that, the solution was condensed by rotary evaporator (Laborata 4000 ) at $35^{\circ} \mathrm{C}$ and finally, the extract was dried under vacuum at $40^{\circ} \mathrm{C}$ by dryer and kept in container, which is enclosed and impervious to air, at $4{ }^{\circ} \mathrm{C}$.

\section{2-2- Measuring the total amount of phenolic compounds of Rheum Ribes flower}

To measure the total amount of phenolic compounds of the extract of Rheum Ribes flower, first, the standard solution of the extract of Rheum Ribes flower was prepared with various concentrations in the range of 100,150,200, 250 and $300 \mathrm{ppm}$ by the solvent that the extract has been extracted by it (methanol) and also control sample was prepared. $0.5 \mathrm{ml}$ of each dilutions were poured in test tubes, which were wrapped by foil, and then, $2.5 \mathrm{ml}$ of normal Folin-Ciocalteu reagent 0.2 (diluted by distilled water at a ratio of 1 to 10) was added to each test tubes. The tubes were vigorously stirred for 30 seconds by tube mixer. Then, $2 \mathrm{ml}$ of sodium carbonate solution $7.5 \%$ was added to them. They were stirred again for 30 seconds at the ambient temperature and kept in the dark place for an hour. The absorption of each test tubes was read at the wavelength of $760 \mathrm{~nm}$ by spectrophotometer. The phenolic compound obtained by the linear regression equation of calibration curve of Gallic acid was determined as a standard $\mathrm{Y}=0.0121 \mathrm{X}-0.0309, \mathrm{R}^{2}=0.9679$ in terms of the Gallic acid (\%). In the regression equation of calibration curve of Gallic acid, $\mathrm{Y}$ is an absorption which read at the wavelength of $765 \mathrm{~nm}$ and $\mathrm{X}$ is the concentration of phenolic compounds (mg/l) (9). 


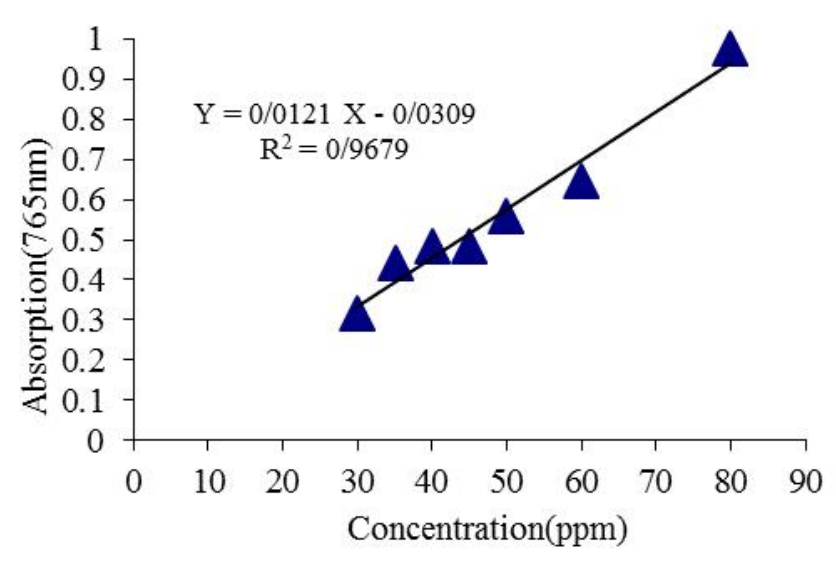

Fig.1. The standard curve of Gallic acid to determine the total amount of phenolic compounds of Rheum Ribes flower extract

\section{3-2- Measuring the free radical scavenging activity (DPPH) of Rheum Ribes flower}

Antioxidant activity evaluation was measured by investigating the 2, 2-diphenyl-1picrylhydrazyl (DPPH) free radical scavenging power. For this purpose, at first, different dilutions of the dried extract of Rheum Ribes flowers including 100, 150, 200, 250 and 300 ppm and also, the control sample with methanol solvent were prepared. The stages briefly are as follows. $2 \mathrm{ml}$ of each of the dilutions was transferred into the test tube and then $2 \mathrm{ml}$ of reagent 2, 2-diphenyl-1-picrylhydrazyl $(0.004 \%)$ was added to each tube and was completely stirred and was kept in the dark for 90 minutes at room temperature and then the absorption of the samples was read out in the wavelength of $517 \mathrm{~nm}$ by the spectrophotometer device. The free radical scavenging power was calculated by using Equation 1(8).

$\mathrm{I} \%=\left(\frac{\mathrm{A}_{\text {Blank }}-\mathrm{A}_{\text {Sample }}}{\mathrm{A}_{\text {Blank }}}\right) \times 100$

In this equation, $A_{B l a n k}$ is the optical density of the control sample (without extract) and $\mathrm{A}_{\text {Sample }}$ is the optical density of different concentrations of the extract. It should be mentioned that in this experiment, 200ppm of synthetic antioxidant (BHT) was used for comparison. 


\section{STATISTICAL ANALYSIS}

Completely randomized statistical design was used in this study. The data was analyzed by SAS software. The mean of data was compared at the level of $95 \%$ by Least Significante Difference (LSD). The Microsoft Excel (version 2003) was used to draw the charts.

\section{RESULTS AND DISCUSSION}

\section{1-4- The amount of phenolic compounds of the Rheum Ribes flower extract}

Since the phenols and phenolic compounds have been widely found in the food and plant products and also due to the importance of their antioxidant activity, they were evaluated in this study. The variance of the effect of antioxidant compounds' concentration on the amount of phenolic compounds was analyzed and the results were showed in Table1. The results showed that the effect of the antioxidants compounds' concentration on the amount of phenolic compounds was significant at the statistical level of $5 \%(\mathrm{p}<0.05)$.

Table1. Analysis of variance of the impact of antioxidant compounds concentration on the amount of phenolic compounds.

\begin{tabular}{|c|c|c|c|c|}
\hline Source of change & $\begin{array}{l}\text { Degree of } \\
\text { freedom }\end{array}$ & $\begin{array}{c}\text { Average of } \\
\text { squares }\end{array}$ & $\begin{array}{c}\text { Amount of } \\
F\end{array}$ & $\mathrm{P}$ \\
\hline $\begin{array}{l}\text { Antioxidant } \\
\text { compounds } \\
\text { concentration }\end{array}$ & 5 & 1391.02 & 174565 & 0.0000 \\
\hline Error & 6 & 0.01 & - & - \\
\hline Total & 11 & - & - & - \\
\hline C.V & 0.15 & - & - & - \\
\hline
\end{tabular}

Given to the significant effect of the antioxidant compounds concentration on the amount of phenolic compounds of the extract of Rheum Ribes flower (Table1), the maximum phenolic compounds was observed with significant difference at the concentration of 300ppm of the extract (Figure 2). Also, the minimum one was observed in control sample. As can be seen, the amount of phenolic compounds had been increased by increasing the concentration of extract from 100 to $300 \mathrm{ppm}$ and also had lead to the increase of antioxidant properties. In a similar 
study, Unver et.al (2009) investigated the antioxidant activity and the total phenol content of methanolic extract of a number of plants and concluded that there is a direct relationship between the amount of total phenols and the antioxidant activity of the extract of these plants, so that in this regard, the plant of Mentha Piperita showed the top rate of total phenols (493 mg equivalent to Gallic acid per gram) and the high antioxidant activity ( $\mathrm{IC}_{50}$ equal to $0.23 \mathrm{mg} / \mathrm{ml}$ ) and the plant of Capparis Ovate showed the low rate of total phenols (185 mg equivalent to Gallic acid per gram) and low antioxidant activity ( $\mathrm{IC}_{50}$ equal to $\left.4.08 \mathrm{mg} / \mathrm{ml}\right)$ (12).Singh et al. (2006) studied the antioxidant properties of the extract and essence of Indian Dill seed. The results showed that the antioxidant activity of its extract is stronger than its essence due to the more amount of Anatole phenolic and Dale Apiol compound (11). Ahmadvand et.al.(2012), have examined the antioxidant properties of hydro-alcoholic extract and the essential oil of Vitex Pseudo-Negundo plant. They reported the total antioxidant capacity of hydro-alcoholic extract and the essence of Vitex Pseudo-negundo which are respectively $1.76 \pm 0.25$ and $2.12 \pm 0.6$ and the amount of phenol in hydro-alcoholic extract and the essence of Vitex Pseudo-negundo are respectively $22 \pm 2$ and $133.11 \pm 3$ (1).

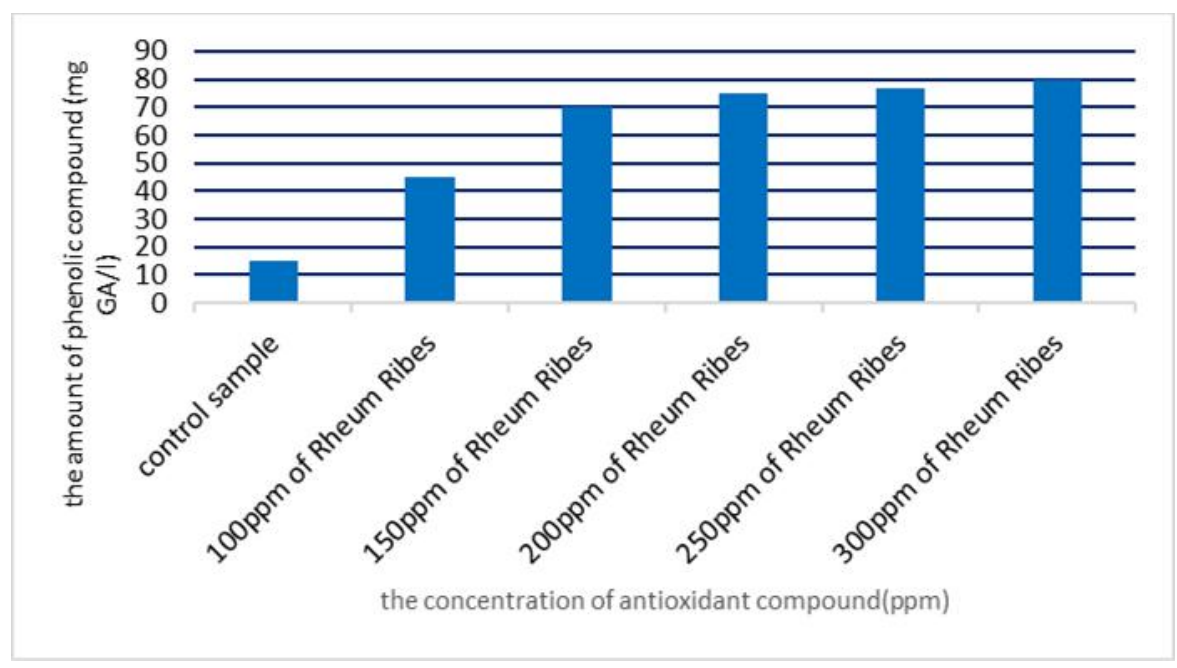

Fig.2. Changes in the amount of phenolic compounds in different concentrations of Rheum Ribes flower extract 


\section{2-4- Radical scavenging activity of Rheum Ribes flower extract}

The variance of the effect of antioxidant compounds concentration and type on the inhibitory activity of free radicals was analyzed and the results were showed in Table2. The results showed that the effect of the antioxidants compounds concentration and type on the inhibitory activity of free radicals was significant at the statistical level of $5 \%(\mathrm{p}<0.05)$.

Table2. The analysis of variance of the impact of type and antioxidant compounds concentration on the free radical scavenging power.

\begin{tabular}{|c|c|c|c|c|}
\hline Sources of change & $\begin{array}{c}\text { Degree of } \\
\text { freedom }\end{array}$ & $\begin{array}{c}\text { Average of } \\
\text { squares }\end{array}$ & Amount of F & $\mathrm{P}$ \\
\hline $\begin{array}{c}\text { Antioxidant } \\
\text { compounds } \\
\text { concentration }\end{array}$ & 6 & 2394.45 & 0.70113 & 0.0000 \\
\hline Error & 7 & 0.03 & - & - \\
\hline Total & 13 & - & - & - \\
\hline C.V & 0.24 & - & - & - \\
\hline
\end{tabular}

Given to the significant effect $(\mathrm{p}<0.05)$ of the antioxidant compounds concentration on the inhibitory activity of free radicals of the extract (Table2), the maximum inhibitory activity of free radicals was observed at the concentration of 300ppm of the extract of Rheum Ribes flower (Figure 3). Also, the results showed that there was no significant differences between the 250 ppm of the extract of Rheum Ribes flower and 200 ppm of synthetic antioxidant of BHT $(\mathrm{p}<0.05)$ (Figure3). The antioxidant effect of the $250 \mathrm{ppm}$ of the extract of Rheum Ribes flower is equvalent to 200ppm of BHT. Azizkhani and Ataei (2012) studied the antioxidant and antimicrobial activities of Mint essence and extract. The results showed that the methanol extract of Mint has more antioxidant activity than its essence in term of inhibitory activity of DPPH and beta-carotene / linoleic acid. Also, they reported that the methanolic extract of Mint reduced the stability of DPPH at the concentration of $55.3 \mathrm{mg} / \mathrm{ml}$, which showed $51 \%$ inhibition. In beta-carotene / linoleic acid, the essence and extract of Mint were able to inhibit the oxidation of linoleic acid and at the concentration of $2 \mathrm{mg} / \mathrm{ml}$, each of them showed $24 \%$ and $36 \%$ inhibition respectively that was much less than the inhibitory activity of BHT (4) . 
Ayoughi (2008) studied the antiradical and antioxidant effect of the essences of Artemisia Dracunculus, Anthemis Tinctoria and Dill. He concluded that the inhibitory activity of the essences of Artemisia Dracunculus, Anthemis Tinctoria and Dill was 57.2, 63.5 and 19.3 $\mathrm{mg} / \mathrm{ml}$, respectively and based on the tests of DPPH and colorless of beta-carotene and also given to the compounds of the essences, the antioxidant activity of Dill was more than the antioxidant activity of Anthemis Tinctoria and the antioxidant activity of Anthemis Tinctoria was more than the antioxidant activity of Artemisia Dracunculus and all of them can be used as a natural antioxidant (5).

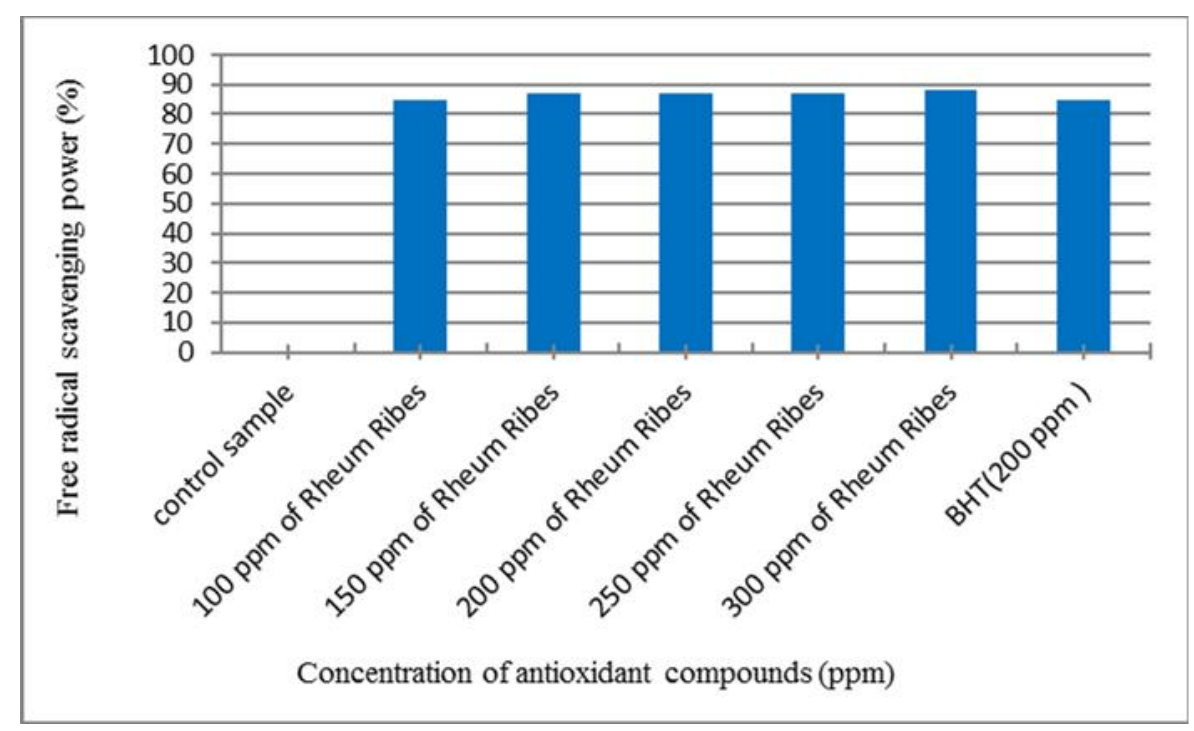

Fig.3. Changes of the free radical scavenging activity in different concentrations of Rheum Ribes flower extract and comparing them with the synthetic antioxidants (BHT).

\section{CONCLUSION}

Today, the use of medicinal plants and their good compounds as a natural sources which have antioxidant properties are concerned by researchers. Antioxidants are the compounds that prevent the reaction of free radicals, which have oxygen and nitrogen, with biological molecules (e.g. protein, amino acids, lipids and DNA ) and reduce the damage of cells or cell death, heart diseases and cancers effectively and in different ways. The synthetic antioxidants such as Butylated hydroxy anisole (BHA), butylated hydroxy toluene (BHT), tertiary butyl hydroquinone (TBHQ) have harmful side-effects. Therefore, the use of natural antioxidants has been concerned greatly. So, the Rheum Ribes flower was investigated as a convenient 
replacement of synthetic antioxidant in this study. The the extract of Rheum Ribes flower with the concentration of $200 \mathrm{ppm}$ and $300 \mathrm{ppm}$ showed the high inhibitory activity of free radicals in compared to the synthetic antioxidant of BHT with the concentration of $200 \mathrm{ppm}$ and the reason is that the Rheum Ribes flower has more phenol compounds and the amount of phenolic compounds and the inhibitory power of free radicals had increased by the increase of the concentration of the extract. In total, the results showed that the extract with the concentration of $300 \mathrm{ppm}$ has the highest antioxidant properties and as a result, it has the highest inhibitory power of free radicals than other concentrations. Also, the results showed that the extract with the concentration of $250 \mathrm{ppm}$ is equivalent to the synthetic antioxidant of BHT with the concentration of $200 \mathrm{ppm}$.

\section{REFERENCES}

[1] Ahmadvand, H., Amiri, H., Ekbatani hamedani, S., Bagheri, Sh. (2012). The ontioxidant properties of the hydroalcoholic extract and essence of Vitex pseudo-negundo's leaf , Journal of Lorestan University of Medical Sciences, 14(2): 5-13

[2] Sharifi, A., Tavakolipour, H. (2008).Optimizing the drying process of Rheum Ribes to prepare powdered Rheum Ribes, $18^{\text {th }}$ National Congress of the food industry, Mashhad.

[3]Shahsavari, N., Barzegar, M., Sahari, M.A. (2008). Evaluation of the antioxidant effect of essences of Zataria multiflora Boiss and Bunium persicum Boiss on the soybean oil, $18^{\text {th }}$ National Congress of the food industry, Mashhad.

[4] Azizkhani, M., Ataei, M. (2012).Evaluation of the antimircobial and antioxidants activities of the essence and extract of mint gathered from the North of Iran, Agricultural science and food industry research, (1):22-26

[5]Ayoughi, F. (2008).Evalution of antiradical and antioxidant effects of the essences of Artemisia dracunculus, Anthemis tinctoria and Dill, M.Sc thesis of Food sciences and technologies, Tarbiat Modarres University, Tehran.

[6]Kamkar, A. (2009).Evalution of the antioxidant activity of the Dill's essence and extract, ournal of Gonabad University of Medical Sciences and Health Services, 15 (2): 17-11 
[7] Bera, D. Lahiri, D.\& Nag, A. (2006).Studies on a natural antioxidant for stabilization of edible oil and comparison with synthetic antioxidants. Journal of Food Engineering,74, $542-545$.

[8] Burits, M. Bucar, F. (2000).Antioxidant activity of Nigella sativa essential oil.

Phytotheraphy Research, 14, 323-328.

[9] Galoburda, R. Kruma, z. \&Ruze, k.(2012).Effect of Pretreatment Method on the Content of Phenolic Compunds, vitamin C and Antioxidant Activity of Dried Dill.World Academy of Sience Enginneering and Technology,64.

[10] Latoui, M., Aliakbarian, B., Casazz, A.A, Seffen, S, Converti, A, Perego, P.( 2012).

Extraction of phenolic compounds from Vitex agnus-castus L.food and bioproducts processing 748-754.

[11] Singh, G and Marimuthu,P. (2006). Antioxidant and biocidal activities of Carum nigrum (seed) essential oil, oleoresin and their selected components. Journal of Agricultural and Food chemistry, 54:174-181.

[12] Unver, A. Arslan, D. Ozcan, M. M.\& Akbulut, M.(2009).Phenolic content and antioxidant activity of some spices. World Appl. Sci. J. 6, 373 - 7.

\section{How to cite this article:}

Nemat Shahi M. M., Elhami Rad A. H., Nemat Shahi N., Bakhsh Amin M. R. Study of antioxidant activity and free radical scavenging power of rheum ribes flower extract. J. Fundam. Appl. Sci., 2016, 8(3S), 1164-1174. 